\title{
Analysis of Urban Rail Transit Seamless Transfer Standard
}

\author{
Liu Li Fen ${ }^{1,2}$ and Wang Wen ${ }^{1}$ \\ ${ }^{1}$ School of Highway, Chang'an University, Xi'an, China \\ ${ }^{2}$ Xi'an municipal design and Research Institute Co., Ltd, Xi'an, China
}

\begin{abstract}
With the improvement of urban rail transit network and traveler requirement of travel, the concept of rail seamless integration has been proposed. This paper analyzes the meaning of integration and seamless integration and the connotation and characteristics of urban rail transport were seamlessly transfer analysis. On this basis, the organization of urban rail transit traffic in different ways are discussed.According to Brighton G (Bou ladon G) hypothesis, tranfer distance is devided into ideal, desirable, acceptable, tolerable, intolerable five levels and their corresponding standard values are quantized, getting the standard of transfer time and distance to evaluate the quality of rail integration and Seamless Transfer of proposeing the standards of integration time and distance.
\end{abstract}

\section{Introduction}

With the development of the city, rail transportation network development is an inevitable direction to play the maximum benefit rail transportation. Transfer trip promotes integrated development of urban public transportation and plays an important role in the rail transport and urban public transport operations. Transfer the merits of transfer system directly affects the rail can play a role, but also directly reflects the rail transportation efficiency and service levels.In the urban rail transit development and travelers for travelers quality improvement background,,urban rail transit seamless transfer concept has been applied in the design of rail transportation, scholars have studied urban rail hubs, city passenger hubs and cohesion layout theoretical model and evaluation of transfer efficiency [1]-[7]. Now the citys of construction rail transit are considering combining with neighboring transit system to facilitate the transfer, to achieve the integration of public transport and seamless transfee, saving transfer time.

\section{The concept, connotation and characteristic of Rail seamless transfer}

\subsection{The concept of Rail seamless transfer}

Urban rail transit transfer system is large and complex, but also provides great convenience to the traveling public. With urban development and travel demand increasing, travel transfers is inevitable. From the perspective of travelers from the starting point to the end to complete a travel, the transfer is the same mode of transport between different vehicles or different modes of transport conversion process in the process of travel.
The transfer of Rail transit network between different line train is the process from one train to another train.Under normal circumstances, for the train and change into the train runs along a fixed line and stop at different stations (except platform transfer), so you need to transfer the vast majority of passengers on foot to achieve. Swapped out trains and swapped trains runs along a fixed line and stop at different stations (except platform transfer), The vast majority of transfers to passengers are achieved by foot.

The transfer between rail transit and external traffic mainly refers to the convergence transfer of rail transit with airports, the city's railway station. The transfer between rail transit and other modes of transportation Mainly involves between conventional bus, taxi, private car, bicycle, walking and other modes of transport interchange.

From the perspective of travelers from the starting point to the end to complete a travel, the transfer is the same mode of transport between different vehicles or different modes of transport conversion process in the process of travel.

So "seamless transfer" refers to the use of the facilities of convergence integration, Minimizing the consumption of transfers between different modes of transportation, including time, money, etc. However, the "seamless" is just an idealized state, even rail traffic in developed countries and regions, can not be fully realized "zero distance" between the modes of transportation. Therefore, from the view of space and time analysis, seamless transfers is to minimize walking and waiting time of passengers and achieve vehicle stable, punctuality. Seamless Transfers is to achieve seamless space, but also time to do seamless. Since walking distance can be measured by time, so seamless transfer, the most important is the time to do a seamless, namely to 
minimize passenger walking time and passenger transfer waiting time.

The most important indicator of evaluating the effectiveness of rail transfer system is to save time, reduce fatigue residents ride line. Transfers efficiency of urban rail transportation hub directly affect the traffic shortcut, and the convenience of travel to hundreds of thousands or even millions of passengers. Therefore, reasonable planning and construction of transfer hub then improving its function, is of great significance.

\subsection{The connotation of urban mass transit seamless}

Urban rail transit seamless transfer refers to the seamless operation phase (such as convergence channel, line, transfer and transfer hall building and the like), but to achieve this convergence must be from the planning, design, construction, operation and manage the entire process to reflect, involving effective coordination of multiple modes of transportation in the city between, seamless transfers hub connotation analysis from the following six aspects.

\subsubsection{Rational layout}

Hubs layout is more to consider when planning the hub from the start thinking, rational layout is more in terms of social, environmental and economic considerations, the layout is more macro level to consider the hub its configuration and coordination with neighboring facilities.

\subsubsection{The capacity matching}

Hubs for point, line, surface configured to consider the integrated transport hub transport capacity through the other modes of transportation unified arrangted and operated on the both in time and space efficient configuration, while providing passengers with a full range of real-time, accurate "seamless" of information services to achieve efficient transport can match.

\subsubsection{Ride facilities are available}

Through scientific and comprehensive system planning and design, and to make the track as the backbone of other modes of transport interchanges pick layout optimization, functional, structured, joint transport network can match the transfer, as a starting point to consider changing take facilities hub configuration, the specific configuration of the facility should be modern information technology and modern management tools based on intelligent infrastructure, automated to meet the travel needs of the urban social and economic development and residents.

\subsubsection{Conducive to the development of surrounding land}

Hub from the planning, it should be with the overall urban planning, network planning, landscape layout to match that transfer hub from the site will begin to take into account the level of land use, which also reflects a seamless transfer is a kind of convergence continued hubs. Energy saving and environmental protection.

First, the entire process from design to operation, it should be considered hubs throughout the layout, the size of the size of the transfer station, transfer facilities and coordinate the relationship between the environment; secondly, from a technical perspective, the need to consider sustainable, low-carbon technologies in the convergence transfer application; and finally, through the development of relevant local laws, regulations and standards to control hubs carbon-related indicators.

\subsubsection{Human services}

Hubs from the entire stages of planning, design, construction, operation and management have to take into account the service of humanity, that is, to consider the convergence of facilities, such as humanized landscape layout, during the operational phase to be considered intelligent infrastructure and staff quality of service, vehicle facility itself user-friendly configuration.

Rational layout, capacity matching, cohesion interchange facilities, conducive to the surrounding land development, environmental protection and human services seamlessly connotation six aspects, including the transfer of transport capacity and efficiency analysis, at the same time reflects the "low-carbon economy, smooth and safe" and other targets.

\subsection{The characteristic of urban rail transit seamless}

\subsection{1 systemic}

Urban rail transit Transfer System is a comprehensive and coordinated system consisting of urban rail transport and other transport modes in two ways by the constitution, but also deals with other outside urban transportation modes of coordination, in addition, other external factors, and these factors mutual restraint, mutual influence, must use viewpoint systematic approach to resolve.

\subsubsection{Integration and hierarchy}

Urban rail transit and other transportation mutual coordination and unified and effective convergence constitutes a seamless transfer, which reflects the overall characteristics; they are both point (hub coordination), line (line network coordination), face (macrocoordination) layer progressive presence in urban public transport system, with a clear hierarchy.

\subsubsection{Dynamic and comprehensive}

Metro convergence is not a static state, is a comprehensive, real-time changes in the state, according to changes in demand requirements, regulatory control parameters, function, structure, layout, economic, policy, 
and so the whole internal and external the system is in a virtuous cycle. So that all aspects of the organic unity of coordination.

\section{Analysis of rail transportation organization}

\subsection{Inter rail transportation organization}

\subsubsection{Non-paid area transfer}

Passengers need to transfer the ticket again, increasing time into the outbound zone transfers formalities unpaid no dedicated transfer facilities, walking long distance passenger and transfer passenger flow lines and other intertwined. Non-paid area transfer, often caused by poor planning, reflecting the mass transit system itself defects, should be avoided.

\subsubsection{Paid district transfers}

Transfer passengers without tickets again, including the platform transfer, the transfer node, the transfer station hall and transfer channels in several ways.

Platform transfer: directly transfer the passengers get off to walk to the other side of the platform, waiting for the train.

Node Transfer: Transfer passengers get off the escalator to reach the floor, use another platform waiting.

Transfer station hall: the transfer of passengers to get off after the first arrival transfer hall, waiting to go to another site.

Channel Transfer: Transfer passengers get off the transfer channel to the other using the platform waiting.

Platform transfer can greatly simplify the transfer flow line is the ideal way to transfer, but the requirements for network planning, circuit design, train operation organization of high and expensive. Node Transfer 、 channel transfer and transfer station halla currently common rail transfer organization, convenience descending order as follows: Node Transfer $>$ channel transfer $>$ transfer station hall. A variety of transfer within the organization can be used in Metro Station.

\subsection{Rail transit and ground conventional public transfer organization}

Conventional Public carrying capacity is relatively small, but the line flexible, broad coverage, applicable to passenger rail hub. Rail and bus transfer organization focuses on: Continuous transfer space and information.

Making mass transit hub design, should be considered a valid ground feeder bus and rail transit, rail transit transfer station near the bus station or the bus station to introduce rail station building, in order to form a comprehensive Hubs hall.

\subsection{Rail Transit and private transport interchange organization}

Private transport including bicycles, private car traffic in several ways. Transfer traffic organization within the rail transportation hub focused on bicycle, private car parking reasonable, including determining the size of parking, planning and service facilities.

High bicycle usage in our country, many cities of the reference residents travel survey, rail transportation hub in densely populated areas, non-motorized transfer is second only to walk the second largest rail transit transfer travel. Therefore, in the planning and design of rail transportation hub, it should consider certain non-motor vehicle parking space, if floor space is limited, you can set up an underground car park. It should also create lanes and facilities equipped with the appropriate model to ensure travelers' safety[8].

For private cars, the parking requirements for higher mass transit hub in urban areas often do not set conditions, can be built in the car parking area is located at the junction of the suburban rail transportation hub, encourage car users to transfer rail into the city, that park and Ride mode $(\mathrm{P}+\mathrm{R})$.

\subsection{Rail and train transfers organizations}

Ideally, if the inner rail transport hub comprising train transportation, urban rail transit should be shared with the train station hall, channels, squares and other facilities, in order to simplify the transfers streamline, improve facility utilization [9]. However, due to differences in vote system, security and other aspects, we can not be fully integration of two modes of transportation. The current urban rail transit train interchange organization there are three main forms:

\subsubsection{Under the square in front of the train station separate building urban rail transit station.}

Rail alignments may be parallel to the railway line, orthogonal, oblique and other two modes of transportation use entrance mutual convergence. The advantage is available Railway Station Square, and cost savings. The disadvantage is that long distance transfers, Station Square Traffic organizational complexity.

3.4.2 in building urban rail transit station and the railway station, the use of integrated hub transfer hall organization transfer.

This method will use a variety of line traffic hub complex in construction, shorten the distance passengers to transfer to simplify plane traffic organization, widely used in the world's major cities.

\subsection{3 transit selected ground-mounted or high shelf, or placed on the side of the railway station square in front of the road and the railway station are arranged in parallel.}

Commonly used method is to organization transfers rail station and the train station connected by channel or overpass. The program covers a smaller rail transit station, 
but traffic interference of different nature, affecting the landscape, transfers mode is not ideal.

\section{Rail seamless transfer standard quantitative research}

Rail transit transfer system to transfer as the main service purpose, namely to ensure that in the case of various modes of transport cross and mixed to achieve passenger flow in the most convenient transfer in the transfer system. As travelers between the same or different mode of transport interchanges generally realized by walking, although sometimes in the civil aviation and subway ride through the track, elevators and other mechanical joint transfer on foot, but by human foot to achieve interchange objectives is essential.

Therefore, walking distance and walk-time transfer function is theoretical basis to quantitative research hubs transfer system.

For this reason, Brighton $\mathrm{G}$ (Bouladon $\mathrm{G}$ ) assumptions is introduced[4]. The function of Walking distance and feel comfortable walking time can be represented as:

$$
T=K d^{r}
$$

$\mathrm{T}$ - transfer walking time

$\mathrm{d}$-Transfer walking distance

$\mathrm{k}, \mathrm{r}$ - coefficient(according to the mode of transportation survey data analysis calculated)

Since travelers inherent individual differences, to transfer distance, transfer time requirements have different standards, so at present, there is no standardized results to comprehensive transportation hub transfer distance and transfer time. In General, taking into account the variety of modes of transportation converge more experience-oriented, but travelers will, cost control, ease of travel into account, always want less time to transfer, transfer distance as short as possible. According to a function within walking distance and walking time, the transfer distance control is divided into five grades, as shown in Table I.

Table 1. Transfer distance classification

\begin{tabular}{|c|l|l|l|l|l|}
\hline grade & A & B & C & D & E \\
\hline description & ideal & desirable & acceptable & tolerable & Intolerable \\
\hline
\end{tabular}

Table 2. k,r,s values of different modes of transport

\begin{tabular}{|c|l|l|l|l|l|l|l|l|}
\hline $\begin{array}{c}\text { Mode of } \\
\text { transportati } \\
\text { on }\end{array}$ & aviation & railway & coach & Rail & taxi & bus & Private car & bicycle \\
\hline $\mathbf{K}$ & 25 & 28.48 & 23.82 & 23.46 & 20.77 & 20.18 & 25.26 & 19.16 \\
\hline $\mathbf{r}$ & 1.32 & 1.25 & 1.3 & 1.55 & 1.22 & 1.33 & 1.46 & 1.51 \\
\hline
\end{tabular}

Normally, traveler requirement for transfer distance and the hub transfer service level evaluation is ambiguous, after the grade division, the transfer distance will be relatively objective and reasonable results. Considering the passenger flow characteristics of different modes of transport, including traffic distribution, passenger walking speed and walking space, whether passengers carrying luggage and other factors, combined with the comprehensive passenger transport hub status quo at home and abroad research data [10], k,r,s values of different modes of transport is initialized, as shown in Table 2.

Some well-known foreign transportation hub in dealing with transfer time, more control in $1 \mathrm{~min}$ completed, or will be controlled within transfer distance $60 \mathrm{~m}$. Learn from the successful experience of foreign countries, combined with the special characteristics of pedestrian traffic that, according to the curve and function of pedestrian flow and density in a horizontal channel of the transport hub to transfer time for standards[6], corresponding to A, B, C, D, E, different levels of traffic transfer time is respectively 90, 90-150, 90-300, 300-480, $>480$, as shown in Table 3.

Table 3. Transfer time classification

\begin{tabular}{|c|c|c|c|c|c|}
\hline transfer Level & A & B & C & D & E \\
\hline description & idael & desirable & acceptable & tolerable & Intolerable \\
\hline Transfer time(s) & 90 & $90-150$ & $150-300$ & $300-800$ & $>480$ \\
\hline
\end{tabular}

According to the characteristics of our country's special pedestrian traffic and the relational model of pedestrian flow parameters in transport hub within different facilities, the transfer system is Classified by transfer time. In the function of walking distance and feel comfortable walking time as the theoretical basis, transfer distance can be obtained under different levels, as shown in Table 4.

Table 4. The rail transit transfer distance under different level

\begin{tabular}{|c|c|c|c|c|c|c|}
\hline \multicolumn{7}{|c|}{ Transfer mode } \\
\hline level & $\begin{array}{c}\text { Coach } \\
(\mathrm{m})\end{array}$ & $\begin{array}{l}\text { Rail } \\
(\mathrm{m})\end{array}$ & $\begin{array}{l}\text { Taxi } \\
(\mathrm{m})\end{array}$ & $\begin{array}{l}\text { Bus } \\
(\mathrm{m})\end{array}$ & $\begin{array}{l}\text { Private } \\
\text { car(m) }\end{array}$ & $\begin{array}{l}\text { Bicy } \\
\text { cle } \\
(\mathrm{m})\end{array}$ \\
\hline $\mathbf{A}$ & 100 & 100 & 80 & 90 & 110 & 50 \\
\hline B & $\begin{array}{l}100- \\
500\end{array}$ & $\begin{array}{l}100- \\
150\end{array}$ & $\begin{array}{l}80- \\
150\end{array}$ & $90-150$ & $\begin{array}{l}110- \\
180\end{array}$ & $\begin{array}{l}50- \\
100\end{array}$ \\
\hline $\mathrm{C}$ & $\begin{array}{l}500- \\
700\end{array}$ & $\begin{array}{l}150- \\
220\end{array}$ & $\begin{array}{l}150- \\
220\end{array}$ & $\begin{array}{l}180- \\
240\end{array}$ & $\begin{array}{l}180- \\
230\end{array}$ & $\begin{array}{l}100- \\
150\end{array}$ \\
\hline D & $\begin{array}{l}700- \\
900 \\
\end{array}$ & $\begin{array}{l}270- \\
370 \\
\end{array}$ & $\begin{array}{l}200- \\
300 \\
\end{array}$ & $\begin{array}{l}240- \\
350\end{array}$ & $\begin{array}{l}230- \\
300 \\
\end{array}$ & $\begin{array}{l}150- \\
220\end{array}$ \\
\hline $\mathbf{E}$ & $>900$ & $>370$ & $>300$ & $>350$ & $>300$ & $>220$ \\
\hline
\end{tabular}

Rail seamless transfer request is a short transfer time and transfer passengers short walking distance. Through the above research, passengers seamless transfer the requirement for seamless transfer is at least an acceptable state and transfer graded should be in c and c and above. Therefore, the interchange time standard of rail seamless transfer should be controlled in $\mathrm{T} \leq 300 \mathrm{~s}$, transfer distance criteria in Table 5.

Table 5. Seamless transfer distance standard

\begin{tabular}{|c|l|l|l|l|l|l|}
\hline $\begin{array}{c}\text { Mode of } \\
\text { transportation }\end{array}$ & coach & Rail & taxi & bus & Private car & bicycle \\
\hline $\begin{array}{c}\text { Walking } \\
\text { distance(m) }\end{array}$ & $<700$ & $<220$ & $<220$ & $<240$ & $<230$ & $<100$ \\
\hline
\end{tabular}


It must be noted that, due to the different ways of transfer walking distance standard is not the same, and transfer distance can probably calculate the walking time, transfer time can not be drawn. Also within walking distance of the transfer will be affected by other factors lead to an increase walking time,such as traffic, channel congestion, wicket mechanical failure and so on. Transfer time includes the walking time and reflects the size of transfer distance, but also can directly describe the ease of transfer.So seamless transfer standard generally use transfer time to reflect.

\section{Conclusion}

With the development of rail transportation and the improvement of people's quality requirements for travel, seamless rail concept has been applied to transportation planning and design. Accroding to application of Brighton hypothesis, transfer distance standards can be divided into five grades, according to the related research, it is concluded that the transfer time and distance under different level standards and Seamless transfer concept. In the final analysis the deficiency of the transfer distance as standard,transfer time should be presented as the standard of seamless transfer.

\section{Acknowledgment}

This work is supported by National High Technology Research and Development Program of China (Project No. 2007AA11Z248) and Chang'an University(Project No. 310821165021) and Traffic Science and Technology Project of Shaanxi Provincial Transport Department (Project No. 15-26K).

\section{References}

1. J. Wang, "Key Issues on Transfer Organization of City Passenger Traffic Hubs," Beijing, Beijing Jiaotong University, 10-32, (2006).

2. D. Li, "Study on Planning and Design Theory for External Passenge Transport Hub of Metropolis," Nanjing, Southeast China University, (2006)

3. J. Su, S. He, "Evaluation of Transfer Efficiency for Urban Rail Transit," Agricultural Equipment \& Vehicle Engineering 12, 22-24, (2009).

4. Y. Wang, "Design Seamless Transfer between Metro Station and Bus:Case Study of on Financial Hi Tech Zone Station on Gu hou - Foshan Line," Tunnel Construction 35, 354-358, (2015)

5. D. Yang, L. Gao, "Exploration of the Threedimensional Traffic Zero Transfer Design of Xi,an Textile CityPassenger Stations," Urbanism and Architecture 33, 5-6, (2014)

6. X. Pan, Z. Ke, "A Study on Transfer D istance and Construction Indexes of Passenger Transit Hubs," Communications Science and Technology Heilongjiang 1, 103-104, (2008).

7. H. Jia, L. Yang, M. Tang, "Pedestrian Flow Characteristics Analysis and Model Parameter Calibration in Canprehensive Transport Teaminal," Journal of Transportation Systems Engineering and Information Technology 5, 117-123, (2009).

8. J. Xu, "Study on Seamless Connection Evaluation of Urban Rail Transit and Bus," Chongqing Jiaotong University, (2014)

9. X. Lu, W. Jiang, "Seamless Connection and Functionalities of Passenger Transport Terminals," Urban Transport of China 12, 1-4, (2014)

10. D. Wu, "Research on Construction of Comprehensive Transportation Hub in the Economic Zone on the West Side of the Straits," Fujian, Fujian Provincial Department of transportation, (2008) 